\title{
NO LIMIAR, UM SUJEITO ENCENA A POÉTICA DE SEBASTIÃO UCHOA LEITE
}

\section{IN THE THRESHOL, A SUBJECT PUTS IN SCENE SEBASTIÃO UCHOA LEITE'S POETICS}

Maria Aparecida JUNQUEIRA ${ }^{1}$

RESUMO: 0 objetivo deste trabalho é apreender a construção do sujeito poético na poesia de Sebastião Uchoa Leite. Orienta-se pelas indagações: Até que ponto este sujeito poético experimenta experiências limiares, buscando apreender na vida moderna as transições, os ritos de passagem do homem do presente? Ao mesmo tempo, que agonia fere-lhe em negatividade ao registrar auto/alterfigurações subjetivas que ficcionalizam identidades de um eu que se espreita e espreita o mundo?

PALAVRAS-CHAVE: Sebastião Uchoa Leite. Poesia. Sujeito poético. Limiar. Negatividade

\begin{abstract}
The objective of this work is to apprehend how the poetic subject is built in Sebastião Uchoa Leite's poetry. The research is guided by the following questions: In which way does this subject try out neighboring experiences, apprehending in modern life the contemporary man's transitions and rites of passage? At the same time that agony hurts him/her in refusals by registering subjective self/ alter
\end{abstract}

${ }^{1}$ Docente do Departamento de Arte e do Programa de Estudos Pós-Graduados em Literatura e Crítica Literária da Pontifícia Universidade Católica de São Paulo (PUC-SP), São Paulo, SP. junqueirama@uol.com.br 
figuring, which transforms identities of a self who spies into himself/herself and spies into the world?

KEYWORDS: Sebastião Uchoa Leite. Poetry. Poetic Subject. Threshold. Negativity

\author{
Fala tu também, \\ fala por último, \\ diz o que tens a dizer. \\ Fala - \\ Mas não separes o Não do Sim. \\ Dá também o sentido ao teu dizer: \\ dá-lhe a sombra. \\ [...] \\ Diz a verdade quem diz a sombra.
}

Mas eis que se atrofia o lugar onde estás:

E agora para onde, despojado de sombra, para onde?

[...] onde se vê a cintilar: na ondulação

de palavras errantes. (Paul Celan, 2014, "Fala tu também")

Poesia é a sombra Em guarda atrás de alguém Ou na frente Abrindo o caminho Diminui ou alonga o vulto Conforme o foco solar Abre-se ou estreita-se No jogo hiperrealista Entre o eu e a margem (Sebastião Uchoa Leite, 2008, "Focos")

Marca, de modo predominante e diverso, a poesia brasileira nas últimas décadas, a figuração corporal do sujeito, traduzida em experiências que constituem subjetividades. Uma delas que chama a atenção é a da poesia de Sebastião Uchoa Leite (1935- 
2003), porque perturba o leitor/espectador os "eus" construídos, expostos e encenados em seus diferentes livros. Desde os primeiros, intitulados Dez sonetos sem matéria (1958-1959), Dez exercícios numa mesa sobre o tempo e o espaço (1958-1962) e Signos/Gnosis e outros (1963-1970), reunidos em Obra em dobras (1960-1988), os sujeitos poéticos já olhavam de soslaio o tempo, o espaço e a distraída presa.

Obliquamente manifestam-se em dramatizações, operando por meio de recusas. O poeta constrói "eus", formando um concerto de vozes dissonantes, que se corporificam em formas híbridas, animalizadas e fantasmagóricas que se conciliam com os desdobramentos ambíguos, complexos do sujeito nestes tempos modernos, unindo-se àqueles poetas que distinguem uma formalimite de poesia ao circunscrevê-la em negatividade nuclear.

0 poeta se mostra artífice construtor do verso ao, de través, apresentar o sujeito lírico em perspectiva crítico-estética. Por isso é possível perguntar se o sujeito poético em Sebastião Uchoa Leite é aquele que experimenta experiências limiares, buscando apreender na vida moderna as transições, os ritos de passagem do homem do presente. Ao mesmo tempo, que agonia fere-lhe em negatividade ao registrar auto/alter-figurações subjetivas que ficcionalizam identidades de um eu que se espreita e espreita o mundo. 0 poeta parece espiar os segredos que recolhe de uma vivência pessoal e histórica, em desajuste e desacordo com a sociedade, em ardil engenhosamente arquitetado. Resta-lhe, via instabilização da linguagem, o resistir por meio de um convergir de forças que revitaliza sua poesia. São vários os caracteres que seu sujeito poético, desdobrado em ambivalências, deixa ver por suspeição.

É em suspeito e em suspenso que se atualiza a subjetividade do eu lírico, repropondo no seu tempo a velha questão do eu e, porque não, do outro. Se no primeiro livro já se nota uma ausência - Dez sonetos sem matéria -, ela se acentua em Dez exercícios numa mesa 
sobre o tempo e o espaço - no qual tempo e espaço são tecidos numa zona intervalar, entre fenomenal e existencial. Acresce-se, aí, a contraposição entre o tempo mítico e o efêmero das coisas: "Deveria pensar nas coisas efêmeras / Incorporo o poste e incorporo a luz / mas a vida permanece opaca", diz na parte III de "Teoria do ócio". Numa zona de duplicidade, salta a indecisão do sujeito, entretanto, os Dez exercícios... parecem conter as sementes que vão antagonizar o absoluto e surpreender a experiência em embates. Por vezes é o que se lê em "Tempus Fugit n. 1": "Compreender que o dia é transeunte, / que a claridade é uma forma de transição. / Todos passeiam na transação do tempo /" ou em "Tempus Fugit n. 2": "As traças devoram / os livros de estampas góticas ou modernas". Essa contraparte efêmera mobiliza o antagonismo e, aos poucos, como as traças, destrói a perspectiva lírica que ali ainda restava e, em seu lugar, imagens do eu alastram-se, em quase dissolução, por sua poesia.

A falta anunciada não se preenche, antes teatraliza-se. Há um vazio que responde a uma ausência presente. Se, no primeiro soneto, de Dez sonetos sem matéria, o tempo é um personagem mítico que se teatraliza: "Clássico tempo, pausa entre dois atos," na poesia, a contar de Antilogia (1972-1979), não só o sujeito lírico, mas o próprio método perfazem-se a espreita, melhor dizendo, como bem frisou João Alexandre Barbosa (2000, p. 27), no prefácio ao livro A espreita, "de espreita, isto é, uma poesia que existe, ainda existe, por entre as frestas da história de desastres e ruínas". Teatraliza-se o sujeito, na ambivalência do esconderijo e do bote, em ação indeterminada de agente ou paciente, de predador ou de presa. A página se faz palco e a dramaticidade do sujeito lírico e da palavra poética é colocada em cena, como em dois poemas exemplares desse mesmo livro A Espreita, ambos escritos em 1997:

\section{Um outro}

(quando acordo no entressono vejo-me 


como se estivesse fora de mim mesmo
é uma espécie de susto:
ali estou eu
parado como se fosse um outro
contratado para cometer um crime
quero voltar para dentro do sono
dentro do subsolo da mente
onde me jogo
e me dissolvo
e me abandono)
(Ele, em geral
Prefere enfiar-se
No canto
Parado
Como uma víbora
Antes do bote
Observa
Calado
O passar do tempo
Pelos relógios
Controlado
Passa pelas folhas
Do livro entreaberto
O úmido
Índice
Do medo)

O poeta, nas frestas entre parênteses, não carrega de significado o poema, mas o enerva de dramaticidade e de violência potencial. Um eu e um ele enervados em "Um outro", que intitula o primeiro poema, e simultaneamente quase dissolve eu e ele em "outro". Ambivalências sob a ótica da suspeição, na zona intermediária do "entressono", entre a vigília e o sono. É no intervalo entre parênteses que o poema acontece e que o poeta aposta na apreensão do movimento em oposição à continuidade, à causalidade temporal. Há apenas vestígios nos poemas de ações possíveis, ecos de falas, vozes dissonantes que sugerem imagens: índices de recusa e 
negatividade. "Passa pelas folhas / Do livro entreaberto / 0 úmido / Índice / Do medo", a linguagem é o lugar da (im)possibilidade de dizer verdades.

A negatividade, em Sebastião Uchoa Leite, corrobora o seu método poético da espreita e parece seguir a lógica da falência, advinda da tradição moderna, que a linguagem, nestes tempos do presente, singulariza em potência. No entressono ou acantoado, parado a observar o tempo e a presa, o ponto de vista do sujeito é traçado no negativo. É a negatividade que lhe alimenta a criação e lhe dá potência para tensionar os paradoxos, mesmo na mais extrema articulação: morte/vida.

Antes mesmo de enunciar-se com radicalidade em $A$ espreita, o sujeito lírico de Sebastião já indagava sobre o nada que somos, em livro publicado em 1982, cujo título Isso não é aquilo (19791982) oculta uma crítica via antilirismo ao "Isso é aquilo", tema emoldurado em metáfora romântica. É sob o prisma de uma charada, entrecruzando a tensão entre "nadas", que, do poema "Igual a uma charada":

\author{
o nada é uma concha \\ uma metáfora encarquilhada \\ encostada à orelha \\ ouve-se nela \\ o ruído igual do vazio \\ deito-me na membrana do nirvana \\ nado no côncavo do nada
}

surge um eu que se entrelaça - "nada" - na possível definição de "nada". Um vazio depurado no continente do ruído, que se explica na elipse. De que é feito este eu poético? Do vazio-cheio nirvanesco: plenitude a que chega o eu na evasão de si - "nado no côncavo do nada" - que é a realização da sabedoria. 0 eu investe na solução de um enigma, construído por entre imagens, sons e sentidos imbricados: "nada", "concha", "côncavo", "orelha", "membrana do nirvana”, "metáfora encarquilhada”. Uma busca poética para a vida, 
um modo ainda que provisório e fascinante de livrar-se da finitude, da tragicidade que envolve a condição humana. A metáfora, aqui, antilírica, encarquilhada, enerveda em nervuras tal qual uma concha, contém o vazio por onde passa o infinito.

É deste vazio que não se dobra a conceituações, que pode emergir sentidos novos, compreensões para fenômenos de articulação difícil. Octavio Paz, quando discute analogia e ironia, em Os filhos do barro, parece fundamentar o sentido estético e crítico desta metáfora poética, revigorada em tal vazio:

0 mundo é a metáfora de uma metáfora. 0 mundo perde sua realidade e se transforma numa figura de linguagem. No centro da analogia há um oco: a pluralidade de textos implica que não há um texto original. Nesse oco se precipitam e desaparecem, simultaneamente, a realidade do mundo e o sentido da linguagem. (PAZ, 2013, p. 79).

A escrita secreta da poesia decifra e cifra o mundo em pluralidade de textos e sentidos. 0 oco se faz método e nele se precipita a nudez do homem diante da morte. Nesta esteira, Sebastião Uchoa Leite não contempla apenas esse oco, mas sente-o e o transforma em matéria poética. Assim, reivindica para o seu sujeito poético não um lugar de saber delimitado interior ou exterior, mas o limiar, onde o rigor da metáfora se concretiza no risco, antagonicamente à linguagem digerível. E, para a sua poesia, reserva os territórios do indeterminado, do intermediário, do suspenso.

Numa perspectiva inversa, portanto, à da ordem contínua, o seu sujeito poético, acentuado nos últimos livros, registra a vida em circunstâncias de risco. Diferente da maioria da poesia dos anos 70, afeita a parâmetros de um cotidiano trivial e um lirismo confessional, como já o frisou Costa Lima (apud SUSSEKIND, 2004, p. 119), a poesia de Sebastião nega tais parâmetros e funda-se no antilírico, no risco, lá onde a língua está fora do poder. No poema "Biografia de uma idéia", do livro Antilogia, o poeta precisa, em medida imprecisa, esse saber, consciente que é de que a linguagem 
é impotente para apreender e superar a negatividade, todavia, é "no centro da analogia" onde "há um oco", que ela iconiza as coisas do mundo. Observe o poema:

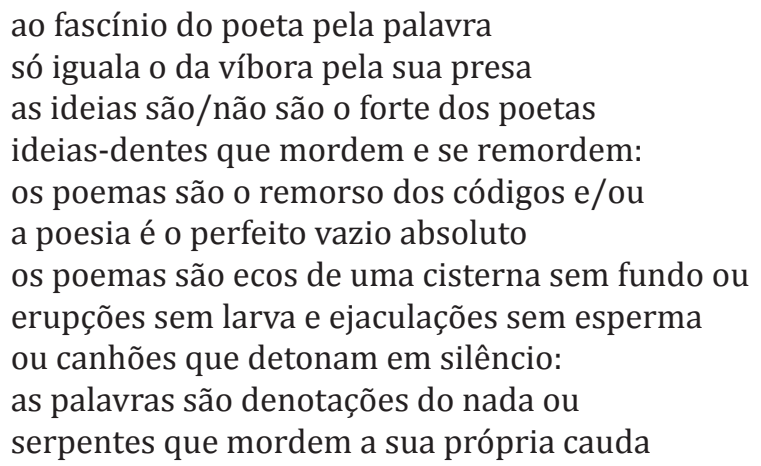

Em comum com a víbora, o poeta tem o veneno contra o uso corrente do idioma. A construção do poema emana do e no negativo. Semântica e sintaticamente ao negar, afirma a linguagem do seu ser. É aí que as "ideias-dentes" trapaceiam a morte e ensinam o viver. Uma luta sem fim da arte diante da finitude da vida. 0 poeta opera com a ausência (a poesia é / os poemas são) - perfeito vazio absoluto, ecos de uma cisterna sem fundo, erupções sem larva, ejaculações sem esperma -, reafirmado pela presença do silêncio, do nada e da forma serpente - "ideias-dentes que mordem e se remordem". É neste processo, embasado na negatividade, que o poeta se põe a pensar e a conceber o fazer poético. Desse modo, poeta e víbora se assemelham no ato de seduzir palavra e presa. Os poemas, longe de transmitirem o fácil, engendram o difícil, "são o remorso dos códigos", apreendem e sugerem o que não se deixa aprisionar em significado, mas em estado de lucidez é um achado.

À moda de Paul Valéry, que toma a imagem da serpente como emblema e afirma: “...Acostumar-se a pensar como Serpente (penser en Serpent) que se come pela cauda. Pois aí está toda a questão. Eu 'contenho' o que me 'contém'. E eu sou sucessivamente continente e conteúdo." (CAMPOS, 1984, p. 113-114); Sebastião também se 
apropria desta imagem e nela encontra a forma para perscrutar o sujeito que devora e é devorado. No poema "Metassombro", de Antilogia se lê:

\author{
eu não sou eu \\ nem o meu reflexo \\ especulo-me na meia-sombra \\ que é meta de claridade \\ distorço-me de intermédio \\ estou fora de foco \\ atrás de minha voz \\ perdi todo o discurso \\ minha língua é ofídica \\ minha figura é a elipse
}

O poeta trata de um eu que volve a si mesmo - eu não sou eu e busca um sentido possível no "não-ser", lugar de conhecimento provável, que alimenta o eu-serpente, cuja cabeça come a própria cauda e ensina o ser a especular-se, a distorcer-se, a estar fora de foco, a perder o discurso e a apoderar-se de uma língua que é ofídica e de uma figura que é a elípse. Língua da poesia. Para Valéry, é o ícone do pensar. Um pensamento que devora a si mesmo, refazendose na procura infinita e rigorosa do ser. Encontro de paradoxos, de probabilidades.

A poesia de Sebastião concretiza este volver-se sobre si com o objetivo de equilibrar a vida diante da dramaticidade do anúncio da finitude feito pela linguagem. A variação desse tema em sua poesia confirma um método, como provam os poemas do livro Cortes/ Toques (1983-1988), primeiro a compor a reunião de sua poesia em Obra em dobras, 1960-1988. Os poemas, escritos respectivamente em 1983 ("Outro esboço") e 1987 (sem titulo, cujo primeiro verso é "Precisamos"), buscam apreender um quase-método que opera por analogia e retém no espaço do mesmo verso semelhanças e desigualdades de fenômenos aparentes. 0 desejo é captar o silêncio primordial e configurar a criação, a invenção, num jogo quase conceitual: 


\section{OUTRO ESBOÇO}

A serpente semântica disse:

não adianta querer

significar-me

neste silvo.

Meu único modo de ser é a in

sinuosidade e a in

sinuação.

Não é possível pensar

a verdade

exceto como veneno.

0 modo de ser poesia e poema é pela (in)sinuosidade e (in) sinuação, apenas sugestão, esboço de sentido, porém, hábil e sutil. A sedução não se aparta deste modo de ser em ondulação, tortuosidade e ardil como o desenho que o poema delineia na página. A advertência do poema - serpente semântica - concretizase de modo dissimulado. 0 modo de ser (in)sinuoso, qualidade primeira do ser serpente, aliado a uma outra qualidade que também lhe dá a especificidade: o veneno, sustentam-lhe o pensar a verdade: "Não é possível pensar / a verdade / exceto como veneno". Há uma qualidade de veneno - agente de transformação - no coração da verdade, aquela que depura o ser em busca de si mesmo. 0 que deseja o poeta senão se aproximar desta inacessível verdade que escapa das mãos do homem? A poesia, todavia, anuncia uma exigência, seu modo de ser é o da obscuridade, seu estatuto, o da ambigüidade. Blanchot (2005, p. 136-137) reitera o poeta: "A verdade da literatura estaria no erro do infinito. 0 mundo onde vivemos, tal como o vivemos, é felizmente limitado. (...) A errância, o fato de estarmos a caminho sem poder jamais nos deter, transformam o finito em infinito." O poeta é aquele que percebe que "A literatura não é uma simples trapaça, é o perigoso poder de ir em direção àquilo que é, pela infinita multiplicidade do imaginário." (BLANCHOT, 2005, p. 140). É o que Sebastião esclarece neste poema: 


\author{
Precisamos \\ de inteligências radar \\ e sonar \\ para captação de formas. \\ A poesia é um repto. \\ Não \\ (necessariamente) \\ um conceito. \\ Uma identificação de ecos \\ por onde o ininteligível \\ se entende.
}

"Ir em direção àquilo que é", à qualidade primeira do ser é pensar por ícones, é captar formas, é desafiar a lei do contínuo para apreender a natureza sensível do objeto. Nesse sentido, são necessárias as inteligências radar e sonar que, semelhantes a equipamentos, são hábeis para localizar objetos em qualquer espaço, apreender-lhes a forma e a natureza, detectar-lhes ecos. Enfim, abstrair as qualidades simples do quase-objeto, forma e sentimento quase ininteligível. Chega-se, então, à poesia, às relações inusitadas, à descoberta do novo, a "Uma identificação de ecos / por onde o ininteligível / se entende".

Entretanto, corre em equívoco aquele que pensa que a poesia de Sebastião se explicita no poema. Não. Ela se segreda, só se deixa ver espiada, sob o mesmo véu que abriga o seu método. Sua intimidade é sutil e enviesada, por isso, simultaneamente, se oculta e mostra, guarda e revela, vigia e escapa. É preciso olhar atento, um saber ver entre luz e sombra para fisgar-lhe os fios que tecem a composição vida/morte numa atitude sempre de espreita. É o que parece dizer o poema, intitulado "Espreita", não por acaso do livro A Espreita:

\author{
É uma espécie de Cérbero \\ Ninguém passa \\ Não escapa nada \\ Olho central \\ Fixo \\ À espreita \\ Boca disfarçada \\ Que engole rápido \\ Sem dar tempo \\ Depois dorme \\ Aplacado
}


Do primeiro ao último verso, a ambiguidade é mantida. Um ser estranho, fantástico, imaginário, espreita e é espreitado, numa confluência do eu e do outro. Uma agressividade exala dos traços mínimos, elípticos, pelos quais é sugerido. Verte ainda uma ameaça que se impõe pela "Boca disfarçada". Como um porteiro do Inferno espécie de Cérbero - cuida de uma passagem, que pode simbolizar, na errância do caminho, o interiorizar-se, o sair de si mesmo, o encontrar-se no outro. Um olho central fixo atrai e é esboçado no corpo do poema - Fixo -, no quinto verso, a delinear também a boca. 0 poema como um todo, todavia, teatraliza o bote à traição da presa. Refestelado e irônico, "Depois dorme / Aplacado".

Alinhada à tradição moderna, a poesia de Sebastião se, por um lado, solicita um observar às ocultas, por outro, há o desejo de trazer à luz, daí o tema luz/sombra que perpassa a poesia do poeta. É neste lusco fusco que o eu e o outro se entrelaçam em imagens instantâneas e ficcionais para um rever-se e ver o mundo. 0 ser de dentro e o de fora em confronto se encontram, resgatados pelo olhar. Num exercício auto-reflexivo, o sujeito poético explora sua identidade em abismo, em figurações como se nota no poema "Enroscado no serpens", do livro Cortes/Toques:

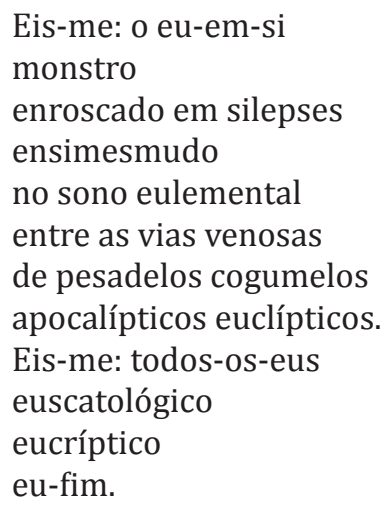

O sujeito poético, em íntima agonia existencial e em humor irônico, afunila-se do primeiro verso - "o eu-em-si" - ao último 
"eu-fim", passando por imagens que tratam dos fins últimos do sujeito e mesmo assim críptico, um eu pouco perceptível, de difícil decifração, que se deixa ver só de espreita, pois prefere "o ignoto" ou o outro, como anuncia no poema "Outro puzzle": "Não estou dentro / A lo mejor, soy outro / (Como disse Vallejo) /À grande dor de estar vivo / (Como disse outro espécime) / Prefiro o ignoto". 0 eu de dentro se identifica com o outro de fora, as realidades de um e de outro se misturam em tensões, segredos que se guardam e que se escapam no âmago da poesia de Sebastião. Outras vezes, mais distanciado, na máscara de uma terceira pessoa, o próprio sujeito poético se busca, como se lê em "Mínima Crítica" n. 5, também de Cortes/Toques:

\author{
O não-herói busca \\ o seu negativo: \\ o seu dentro Jack-the-ripper \\ que não quisesse \\ apenas matar. \\ Mas muito mais: \\ ver de fora as tripas.
}

Já de início o poema revela uma das faces/ficções negativas do sujeito, um não-herói que busca o seu negativo. Um negativo que não opera com o seu oposto, mas com a intensidade do negar. Num jogo no qual dentro e fora são expostos: inerente ao interno é a memória do assassino inglês Jack, o estripador, a negatividade do fora é ver as tripas. Ambiguidade que desconcerta o leitor/espectador que espera a relação positivo/negativo, mas o que lhe é dado a ver é mais violência: do âmago da vítima, as vísceras - selvageria irônica do anti-herói em perspectiva oblíqua.

Eu e outro na poesia de Sebastião experimentam essas zonas identitárias ambíguas e descontínuas que geram desfigurações do sujeito poético. No livro $A$ espreita, numerosos poemas radicalizam esta espionagem do vazio interior do eu e do outro, cuja reconfiguração se constrói nas sombras, embora aspire a luz. 
Trata-se de uma interioridade esvaziada, entretanto, o poema ainda retém algo em segredo que se move entre o dentro e o fora, difícil de abstrair, no entanto, é o que torna o poeta singular. 0 poema "A luz na sombra" é exemplo:

Súbito - do outro lado -
Vejo-o projetado
No espaço
Deste lado
Os focos sobre almofadas
Uma luz amarela
Os quadros também
Esquálido
Amarelomagro
Na sombra
Do além-vidro
Vida em-si
Universo invisível
Vazio
Corpo absorto
Em queda
Na sombra-silêncio

A quem se dirige, em terceira pessoa, o sujeito poético de "A luz na sombra"? Ao eu lírico herdado da tradição lírica e escamoteado, subtraído na modernidade? A um eu que se vê projetado "do outro lado" ou "deste lado"? A localidade se indetermina e uma imagem se teatraliza, não simplesmente no espaço que simultaneamente divide e integra o ser na zona limiar. Mais que isso: aqui parece não existir qualquer distância - um é outro -, rasga-se a interioridade, escarna-se o sujeito e quase se expõe a alma, se ela pudesse ser vista. Mas o que se vê em "Os focos sobre almofadas / Uma luz amarela / Os quadros também / Esquálido / Amarelomagro /", quando pela obscuridade/claridade de "Na sombra / Do além-vidro" tudo se torna opaco? Luminosidade difusa e opaca entranha pelo peso e cor - luz amarela, esquálido, amarelomagro - palidez, macilência, morte. Sensação de ambiguidade que oblitera a visão e ofusca ver a "Vida-em-si". Se no passado o em-si, mesmo inapreensível, 
fundou o ser e inventou uma individualidade representada ainda pelo eu lírico, construído na relação sujeito e objeto, o presente, como lembra Haroldo de Campos, e prefere expressá-lo pelo termo "agoridade" / Jetztzeit (caro a Walter Benjamin), [é]:

uma poesia "do outro presente" e da "história plural", que implica uma "crítica do futuro" e de seus paraísos sistemáticos. Frente à pretensão monológica da palavra única e da última palavra, frente ao absolutismo de um "interpretante final" que estanque a "semiose infinita" dos processos sígnicos e se hipostasie no porvir messiânico, o presente não conhece senão sínteses provisórias (CAMPOS, 1997, p. 269).

"A luz na sombra" é uma síntese provisória proposta por Sebastião Uchoa Leite que, atento à transformação do sujeito poético e espreitando o mundo, esvazia o em-si e o projeta na plenitude do vazio - Universo invisível / Vazio - não afeito à visão, mas à tragicidade da "agoridade" da vida. Surpreende o eu, o outro e o leitor/espectador, sujeitos viventes deste tempo, que apreendem (mesmo amarelomagro) o instante pelo olhar - "Vejo-o projetado / No espaço (...) Corpo absorto / Em queda / Na sombrasilêncio". A ausência de uma ação ou gesto, contudo, não neutraliza a presença de um eu/outro esquálido, metamorfoseado no trágico, cuja consciência continua a velar de espreita a si mesmo, o homem e o mundo. É nessa zona limiar e estratégica que o poeta se encontra com Paul Celan (2014, p. 35) de "Fala tu também": "Fala - / Mas não separes o Não do Sim. / Dá também o sentido ao teu dizer: / dá-lhe a sombra".

"(...) despojado de sombra, para onde?" se pergunta o sujeito poético de Celan (2014, p. 35). E sugere ao tu:

Sobe. Tacteia para cima.

Tornas-te mais delgado, mais irreconhecível, mais fino!

Mais fino: um fio,

por onde ela quer descer, a estrela: 
para nadar lá em baixo, lá em baixo, onde se vê a cintilar: na ondulação de palavras errantes.

Entre o subir e o descer, o sujeito poético experimenta abismos infinitos, metamorfoseia-se, torna-se quase irreconhecível - Mais fino: um fio - (fino fio concretizado no verso do poema) ou como diz o sujeito poético de Sebastião: “Esquálido / Amarelomagro", para responder ao desejo da estrela / poesia: nadar lá embaixo e ver-se cintilar "na ondulação / de palavras errantes", lá onde a linguagem se preserva da cisão Sim e Não. Na sombra. Na marginalidade. No limiar da doxa.

É na errância, cujo não lugar é o limiar, que a poesia ancora sua promessa de vida, e a poesia de Sebastião revela que "Aquilo que se mostra no limiar entre ser e não ser, entre sensível e inteligível, entre palavra e coisa, não é o abismo incolor do nada, mas o raio luminoso do possível." (AGAMBEN, 2007, p. 30). Retorna-se, então, à epígrafe: "Poesia é a sombra / Em guarda atrás de alguém / Ou na frente / abrindo o caminho (...) / No jogo hiperrealista / Entre o eu e a margem" (LEITE, 2008, p. 22).

O sujeito poético de Sebastião Uchoa Leite mantém-se, assim, no limiar, lugar de indeterminação onde o sujeito se desveste do lirismo pessoal e potencializa novas estruturas de linguagem. 0 poeta investe o eu de teatralidade, colocando-o para encenar dados e relações inesperadas extraídos da realidade. Uma espécie de sujeito poético que constrói a "própria sombra a partir dos valores luminosos da palavra". A imagem que sugere é a de um ator/ personagem que se sabe "restos e fragmentos de uma história" (BARBOSA, 2000, p. 25, 16). Coaduna-se com a tradição moderna da negatividade e ainda potencializa, em oculto, para o eu/outro, vértices inusitados de sombra e luz que o olhar do leitor/espectador e o do próprio sujeito poético experimenta de viés e aprende com o poeta o sentido estético e crítico da vida e da arte em nudez frente à morte. Como também o poeta põe em cena no poema "Teatro", de A espreita: 


Ali - a luz vermelha
Aqui - olhos que vêem
De viés
Na diagonal deste ângulo
Um teatro de sombras
Sobrângulos
Destes olhos
Conscientes e senscientes
Fixados na luz
De formas
Indecifradas

que os sujeitos captam na apresentação de si e no registro do mundo, em campo de indeterminação: uma forma de apreender a subjetividade por sua subtração, nesses tempos em que "o presente não conhece senão sínteses provisórias".

\section{REFERÊNCIAS BIBLIOGRÁFICAS}

AGAMBEN, G. Bartleby: escrita da potência. "Bartleby, ou Da Contingência" seguido de Bartleby, o escrivão de Herman Melville. Trad. de "Bartleby, ou Da Contingência": Manuel Rodrigues e Pedro A. H. Paixão (2007). Trad. de Bartleby, o escrivão: Gil de Carvalho (1988). Edição de Giorgio Agamben e Pedro A. H. Paixão. Lisboa: Assírio \& Alvim, 2007. (Arte e produção / disciplina sem nome. Coleção dirigida por Pedro A. H. Paixão).

BARBOSA, J. A. Raro entre os raros. IN: LEITE, Sebastião Uchoa, A espreita. 1. ed. São Paulo: Perspectiva, 2000. (Coleção Signos, 27).

BLANCHOT, M. 0 livro por vir. 1. ed. Trad. Leyla PerroneMoisés. São Paulo: Martins Fontes, 2005. 
CAMPOS, A. Paul Valéry: A serpente e o pensar. 1. ed. São Paulo: Brasiliense, 1984.

CAMPOS, H. Poesia e modernidade: da morte da arte à constelação, o poema pós-utópico. In: 0 arco-íris branco: ensaios de literatura e cultura. 1. ed. Rio de Janeiro: Imago, 1997, p. 243-269. (Biblioteca Pierre Menard).

CELAN, P. Não sabemos mesmo o que importa - Cem poemas. 1. ed. Trad. e posfácio de Gilda Lopes Encarnação. Lisboa: Relógio D’ Água Editores, 2014.

LEITE, S. U. Obra em dobras, (1960-1988). 1. ed. São Paulo: Duas Cidades, 1988. (Coleção Claro Enigma).

. Cortes/Toques (1983-1988). In: . Obra em dobras, (1960-1988). 1.ed. São Paulo: Duas Cidades, 1988 p. 7-54. (Coleção Claro Enigma).

. Isso não é aquilo (1979-1982). In: . Obra em dobras, (1960-1988). 1.ed. São Paulo: Duas Cidades, 1988, p. 55-105. (Coleção Claro Enigma).

. Antilogia (1972-1979). In: . Obra em dobras, (1960-1988). 1.ed. São Paulo: Duas Cidades, 1988, p. 107141. (Coleção Claro Enigma).

A espreita. 1. ed. São Paulo: Perspectiva, 2000. (Coleção Signos, 27). 
LEITE, S. U. A uma incógnita: 1989/1990. 1. ed. São Paulo: Iluminuras, 2008.

PAZ, 0. Os filhos do barro: do romantismo à vanguarda. 1 . ed. Trad. Ari Roitman e Paulina Wacht. São Paulo: Cosac Naify, 2013.

SUSSEKIND, F. Literatura e vida literária: polêmicas, diários \& retratos. 2. ed. Belo Horizonte: Editora UFMG, 2004. 
50 - Revista Texto Poético | ISSN: 1808-5385 | Vol. 16 (1º sem-2014) | p. 31-50 